1 Peat-wood fly ash as cold-region supplementary cementitious

2 material: Air content and freeze-thaw resistance of air-entrained

3 mortars

4

5 Rissanen Jouni ${ }^{\text {a }}$, Ohenoja Katja ${ }^{\text {b* }}$, Kinnunen Paivo ${ }^{c}$, and Illikainen Mirja ${ }^{d}$

6

$7{ }^{a}$ M.Sc, Fibre and Particle Engineering, Faculty of Technology, P.O. Box 4300,

8 90014, University of Oulu, Finland, e-mail: jouni.rissanen@oulu.fi

$9{ }^{b}$ D.Sc., Fibre and Particle Engineering, Faculty of Technology, PO Box 4300,

10 90014, University of Oulu, Finland, e-mail: katja.ohenoja@oulu.fi

$11{ }^{c}$ Ph.D., Fibre and Particle Engineering, Faculty of Technology, PO Box 4300,

1290014 , University of Oulu, Finland, e-mail: paivo.kinnunen@oulu.fi

$13{ }^{d}$ Professor, Fibre and Particle Engineering, Faculty of Technology, PO Box 4300,

14 90014, University of Oulu, Finland, e-mail: mirja.illikainen@oulu.fi

$15 *$ Corresponding author, e-mail: katja.ohenoja@oulu.fi, tel.: +358294482395

\title{
16 Abstract
}

17 Fluidized bed combustion fly ash (FBCFA) is a promising industrial side stream to

18 be used as a partial cement replacement material. Untreated and milled FBCFAs

19 from co-combustion of peat and wood were used to replace $20 \%$ of Portland cement

20 in air-entrained and non-air-entrained mortars. Additionally, equivalent mortars

21 containing fly ash from pulverized coal combustion (CFA) were prepared to

22 compare FBCFAs to more conventional, standardized cement replacement

23 material. The study found that both FBCFAs produced mortars with similar

24 compressive strengths compared to a reference, indicating that milling did not affect

25 reactivity of ashes. Air-entrained FBCFA-containing mortars had about the same

26 amount of entrained air compared to the reference mortar. FBCFAs outperformed 
27 CFA as a cement replacement material, which produced lower compressive 28 strengths and reduced the amount of entrained air. Non-air-entrained mortar 29 containing CFA suffered severe damage during the freeze-thaw (F-T) experiment, 30 unlike non-air-entrained mortars containing untreated or milled FBCFA. The 31 addition of an air-entrainment agent improved F-T resistance of all mortars, except 32 those that contained milled FBCFA, which nevertheless had good F-T resistance.

33 This first-of-its-kind investigation of the suitability of peat-wood FBCFAs as a

34 supplementary cementitious material in air-entrained mortars suggests a potential 35 use of FBCFAs in cold region concreting.

36

37 Keywords: sustainable concrete, frost resistance, frost damage, biomass ash, 38 grinding, air content

39 


\section{Introduction}

41 During recent decades, fluidized bed combustion (FBC) has gained popularity

42 around the world due to its suitability for various fuels that may have fluctuations

43 in quality, such as biomass, peat, municipal waste, and low rank coal. Compared to

44 pulverized combustion, FBC can produce less NOx due to lower combustion

45 temperature, and SOx emissions can be mitigated by injecting limestone into a

46 boiler, which adsorbs sulfur compounds. The current challenge of FBC is that it

47 produces fly ashes with variable quality, no standardization, and unestablished

48 utilization. One potential way to utilize high volumes of FBC fly ash is to use it as

49 supplementary cementitious material (SCM), which has already shown promising

50 results (Rajamma et al. 2015; Rissanen et al. 2017; Sata et al. 2007; Sheng et al.

51 2007; Wang and Song 2016; Zhao et al. 2015).

52 In cold climates, concrete is often exposed to recurring freezing. This damages the

53 concrete because during the freezing process, water expands and causes internal

54 stress to the material. This stress eventually leads to deterioration of the concrete

55 if internal stress exceeds the strength of the material. Frost damage of concrete

56 can be avoided if concrete can be kept dry, but in practice, this is often

57 impossible. Concrete's resistance against frost damage can be improved by using

58 air-entrainment agents (AEAs), which are surface-active chemicals. AEAs induce

59 small and well-dispersed bubbles into fresh concrete, and these bubbles remain

60 air-filled during the curing. Typical air content for freeze-resistant concrete is 5-

$616 \%$ (Hewlett 2003) while air content for air-entrained mortar mortar is around 8-

62 21\% (“ASTM C91-05, Standard Specification for Masonry Cement” 2005;

63 Dransfield 2003; Hewlett 2003). In hardened concrete, pores formed from bubbles

64 protect concrete by reducing internal stress caused by freezing water. The basis

65 for this phenomenon is that air in these pores contracts as temperature decreases, 
66 thereby relieving the stress caused by freezing water. Additionally, part of the

67 freezing water can escape from capillary pores into these air voids where it cannot

68 cause damage.

69 It is well known that conventional fly ashes originating from pulverized coal

70 combustion (PCC) can interfere with the performance of AEAs, because they often

71 contain unburned carbon. This carbon can absorb molecules in AEA, reducing the

72 amount of effective AEA molecules (Gao et al. 1997; Hill et al. 1997). Similar

73 behavior has also been observed with granulated ground blast furnace slag and

74 silica fume (Cyr 2013). PCC fly ash can also increase surface scaling of concrete

75 (Cyr 2013).

76 In air-entrained concretes, cement replacement using fly ash from co-

77 combustion of biomass and coal have been reported to cause similar problems as

78 conventional fly ash from PCC. Fly ash from co-combustion biomass and coal has

79 been reported to increase the requirement for AEA (Shearer et al. 2010; Wang et al.

80 2008), decrease the effectiveness of AEA (Kosior-Kazberuk and Józwiak-

81 Niedzwiedzka 2010), decrease the quality of air entrainment, (Kosior-Kazberuk and

82 Józwiak-Niedzwiedzka 2010) and decrease the surface scaling resistance of

83 concrete (Kosior-Kazberuk and Józwiak-Niedzwiedzka 2010; Kosior-Kazberuk

84 2013). Contrary to this, Johnson et al. (2010) reported that fly ashes with low loss

85 on ignition (LOI) $(0.4-0.9 \%)$ did not interfere with the performance of the AEA. It

86 is possible that properties of co-combustion fly ash are closer to the properties of

87 conventional coal fly ash because biomass can have a negligible effect on ash

88 quality due to its lower ash content compared to coal (Johnson et al. 2010).

89 In air-entrained concrete, cement replacement by fluidized bed combustion

90 fly ash (FBCFA) from combustion of coal has been reported to increase AEA

91 dosage of concrete (Glinicki and Zielinski 2008) and to decrease surface scaling 
92 resistance (Glinicki and Zielinski 2009). Both positive (Józwiak-Niedźwiedzka

93 2012) and negative (Glinicki and Zielinski 2008) effects on the quality of the air

94 void system have been reported. In addition, one study reported that FBCFA from

95 coal combustion decreased freeze-thaw $(\mathrm{F}-\mathrm{T})$ resistance of non-air-entrained

96 concrete (Naik et al. 2005). Omran et al. (2018) reported that concretes in which

$97 \quad 15-25 \%$ of the cement was replaced by FBCFA from biomass combustion had good

98 F-T durability. On the other hand, FBCFA had a negative effect on surface scaling

99 resistance and spacing factor.

100 In addition, there are studies that used fly ash from biomass combustion, but

101 the combustion method has not been stated. Wang et al. (2008) reported that pure

102 wood fly ash did not increase AEA dosage in a similar way as ashes from coal

103 combustion and co-combustion of coal and biomass. Nagrockienè and Daugèla

104 (2018) used fly ash from biomass combustion to replace 5-30\% of cement. At a

105 replacement rate of $15-20 \%$, properties related to F-T resistance, such as

106 compressive strength and open and closed properties, were at the same or better

107 level than in the reference mix. Researchers noted that up to the $15 \%$ replacement

108 level, concrete had the same or better predicted durability than the reference mix.

109 Ipatti (1988) examined the effect of peat fly ash to the freeze-resistance of concrete.

110 That study reported that cement replacement using peat fly ash in air-entrained

111 concrete resulted in increased compressive strength and good freeze resistance.

112 Used fly ash had a high $\mathrm{SiO}_{2}$ content (62\%) and low LOI (0.46\%).

113 Overall, research focusing on other than pulverized coal fly ashes is quite

114 limited, and most of these studies have been done for fly ashes originating from

115 FBC of coal or from co-combustion of coal and biomass. However, it is known that

116 both combustion method and fuel significantly affect the physical and chemical 
117 properties of fly ash, which in turn affects fresh and hardened state properties of 118 concrete and mortar.

119 The aim of this study was to examine how partial cement replacement using 120 un-treated and milled FBCFA from co-combustion of peat and wood affects AEA 121 performance and F-T resistance of conventional and air-entrained mortars. These

122 are important properties, especially in cold regions where peat and biomass are 123 available for energy production. Additionally, fly ash from pulverized coal 124 combustion was used to compare the performance of FBCFA to a more 125 conventional, standardized SCM.

\section{Materials}

127 FBCFA used in this study originated from circular FBC of peat and wood. The 128 burning temperature in the boiler was around $790^{\circ} \mathrm{C}$. In order to study the effect of 129 milling, FBCFA was milled using a laboratory size tumbling ball mill. A small

130 amount of isopropanol was used as a grinding aid to prevent the agglomeration of

131 fly ash during the milling. Milling was continued to the point where median particle 132 size of ash remained constant. Milled FBCFA is referred to as M_FBCFA. Coal fly 133 ash (CFA), originating from pulverized combustion of coal, was used to compare 134 the performance of FBCFA to a more conventional SMC. Cement used in this study 135 was sulfate resistant Portland cement type CEM I 42,5 N -3R (SR-sementti, 136 Finnsementti). Sand used in mortars was CEN Standard sand (CEN-Standard Sand, 137 Normensand $\mathrm{GmbH}$ ). The AEA used was in liquid form and it was based on 138 synthetic tensides (Airmix, Finnsementti). The super plasticizer (SP) used in the 139 mortars was polycarboxylate based (SemFlow ELE 20, Semtu). 


\section{Methods}

\section{Characterization of materials}

142 Chemical composition of materials was determined using the X-ray fluorescence

143 method (XRF). Analysis was done for melt-fused tablets using a wavelength

144 dispersive XRF spectrometer (AxiosmAX, PANalytical). LOI was measured by the

145 thermogravimetric method using an automatic drying and ashing system (prepASH,

146 Precisa Gravimetrics AG). Carbon content of the fly ashes was measured using

147 CHNS/O elemental analyzer (2400 Series II CHNS/O Analyzer, PerkinElmer).

148 Particle size distribution (PSD) of cement replacement materials was analyzed

149 using a laser diffraction particle size analyzer (LS 13 320, Beckman Coulter).

150 Analysis was done in wet mode using isopropanol as a carrier medium, and the data

151 were analyzed using the Fraunhofer optical model. Density of materials was

152 measured using a helium pycnometer (AccuPyc II 1340, Micromeritics).

\section{Mix design}

154 Mortar mix design was based on the EN 196-1 testing standard (SFS 2016).

155 However, some modifications were made. To study the effect of cement 156 replacement using FBCFA, M-FBCFA, and CFA, a 20\% mass based replacement

157 rate was selected. SP was used in every sample, and dosage of SP was based on pre158 experiments so that the mixtures without AEA would have approximately the same 159 workability. Five different levels of AEA were used to produce mortars with 160 different air contents. A water-to-powder ratio of 0.45 , instead of the original 0.5 , 161 was selected to prevent mortars from having too high flowability. The mix designs 162 of the various mortars are presented in Table 1. 


\section{Mortar mixing}

164 The mixing of mortars was done according to cement testing standard SFS-EN 196-

1651 (SFS 2016). Immediately after mixing, the flowability of mortars was evaluated 166 using the flow table method described in standard SFS-EN 1015-3 (SFS 1999).

167 Next, mortar was mixed in the mixer for one minute using a fast mixing speed.

168 Immediately after the mixing, the density of the mortar was measured using two

169 identical cylinder-shaped plastic containers. First, half of the cylinders were filled

170 with mortar, and then the mortar was compacted using a tamper. After this, the

171 cylinders were set on a jolting apparatus described in SFS-EN 196-1 (SFS 2016)

172 and jolted 60 times to remove excess air from the mortar. Finally, the rest of the

173 containers were filled with mortar and the same compaction procedure was used.

174 After filling the containers, the surface of the mortar was leveled and all the excess

175 material was removed from the sides of the containers. The weights of the empty

176 and full containers were recorded. After the weighing of the cylinders, mortar was

177 loaded back into the mixer and mixing was continued for 30 seconds at a fast mixing

178 speed. Finally the casting of the mortar was done according to SFS-EN 196-1 (SFS

179 2016). After the casting, the mortars were wrapped in plastic and cured under

180 laboratory conditions. The next day, the mortars were removed from molds and 181 cured in plastic containers filled with water.

182 Air content

183 Air content of the mortars was calculated by comparing the real density of fresh 184 mortar, $\rho_{R}$, to theoretical density similar to the ASTM C138 standard (ASTM 2017).

185 However, measurement devices and protocols of standards were modified to be 186 more suitable for lab scale experiments done with mortar.

187 The density of fresh mortar, $\rho_{\text {Fresh }}$, was calculated using equation (1). 
$188 \rho_{\text {Fresh }}=\frac{M_{\text {Mortar }}}{V_{\text {Mortar }}}$,

189 where $\mathrm{M}_{\text {Mortar }}$ is mass of mortar in the container and $\mathrm{V}_{\text {Mortar }}$ is the volume of the 190 container.

191 The theoretical density of mortar, $\rho_{\text {Theoretical, was calculated using equation }}$

192 (2).

$193 \quad \rho_{\text {Theoretical }}=\frac{M_{\text {Total }}}{\frac{M_{C}}{\rho_{C}}+\frac{M_{W}}{\rho_{W}}+\frac{M_{S}}{\rho_{S}}+\frac{M_{R}}{\rho_{R}}+\frac{M_{A E A}}{\rho_{A E A}}+\frac{M_{S P}}{\rho_{S P}}}$,

194 where $\mathrm{M}_{\text {Total }}$ is total mass of mortar mixture, $\mathrm{M}_{\mathrm{C}}$ is mass of cement, $\rho_{\mathrm{C}}$ is density of

195 cement, $M_{w}$ is mass of water, $\rho_{\mathrm{W}}$ is density of water, $M_{\mathrm{S}}$ is mass of sand, $\rho_{\mathrm{S}}$ is

196 density of sand, $M_{R}$ is mass of used replacement material, $\rho_{R}$ is density of

197 corresponding replacement material, $\mathrm{M}_{\mathrm{AEA}}$ is mass of AEA, $\rho_{\mathrm{AEA}}$ is density of AEA,

$198 \mathrm{M}_{\mathrm{SP}}$ is mass of SP, and $\rho_{\mathrm{SP}}$ is density of SP.

199 Finally, the air content of fresh mortar was calculated using equation (3).

200 Air content $(\%)=\left(\frac{\rho_{\text {Theoretical }}-\rho_{\text {Fresh }}}{\rho_{\text {Theoretical }}}\right) \times 100$

\section{Freeze-thaw resistance}

202 To study the mortar's resistance against damage caused by repetitious freezing and

203 thawing, mortars were exposed to 90 F-T cycles. The experiment was modified 204 from ASTM standard C-666 (ASTM 2015). After the mortars were cured 28 days, 205 they were put in small plastic boxes (three prisms per box) and water was added to 206 the box so that mortars were half immersed in water during the experiment. F-T 207 cycles were produced in a climatic test chamber (WK3-180/40, Weiss Technik). At 208 the beginning of the F-T cycle, temperature was first kept at $15^{\circ} \mathrm{C}$ for two hours. 209 During the next two hours, the temperature was dropped to $-20^{\circ} \mathrm{C}$ where it stayed 210 another two hours. Finally, during the last two hours, the temperature was raised 
211 back to $15^{\circ} \mathrm{C}$. Specimen Ref.0.05 was not subjected to F-T-experiment due to an

212 error in sample handling.

213 Evaluation of mortars' F-T resistance was based on compressive strength

214 and relative dynamic modulus of elasticity, determined before and after the F-T

215 experiments. The relative dynamic modulus of elasticity was obtained using an

216 ultrasonic pulse velocity tester (Ultrasonic pulse velocity tester, Matest) which

217 measured the time of an ultrasonic pulse going through mortar samples. These

218 measurements were made before and after the samples were exposed to F-T cycles

219 and during the experiment at intervals of 18 cycles. Specimens were removed from

220 the climatic test chamber approximately 24 hours before measurement and kept

221 fully immersed in water at room temperature. After measurement, the specimens

222 were returned to the F-T cabinet and the experiment was continued. The relative

223 dynamic modulus of elasticity was calculated using equation (4).

224 Relative dynamic modulus of elasticity $(\%)=100 \times \frac{V_{n}^{2}}{V_{0}^{2}}$,

225 where $V_{n}$ is the velocity of ultrasonic pulse after $n$ F-T cycles and $V_{0}$ is the velocity 226 of pulse before F-T experiments.

227 After 90 F-T cycles, the compressive strengths of the mortars were 228 determined and compared to the compressive strengths of corresponding mixtures 229 (on the 28th day), which were not exposed to F-T cycles. Finally, F-T resistance 230 was calculated using equation (5).

231 Freeze-thaw resistance $(\%)=100 \times \frac{f_{c f t}}{f_{c 28}}$,

232 where $f_{c f t}$ is compressive strength after the F-T experiment and $f_{c 28}$ is compressive 233 strength after 28 days curing. 


\section{Results and discussion}

\section{Characterization of materials}

236 FBCFA consisted mainly of $\mathrm{SiO}_{2}, \mathrm{Fe}_{2} \mathrm{O}_{3}, \mathrm{Al}_{2} \mathrm{O}_{3}$, and $\mathrm{CaO}$ (see Table 2). The sum 237 of $\mathrm{SiO}_{2}, \mathrm{Al}_{2} \mathrm{O}_{3}$, and $\mathrm{Fe}_{2} \mathrm{O}_{3}$ was $72.6 \%$ which fulfills the requirement of fly ash 238 standard EN 450-1 (SFS 2013). FBCFA had 1.5\% LOI value and 0.3\% carbon 239 content. FBCFA contained $3.5 \% \mathrm{SO}_{3}$, which is slightly higher than the limit of fly 240 ash standard EN 450-1. Otherwise, FBCFA fulfilled the chemical requirements of 241 EN-450-1. CFA was mainly composed of $\mathrm{SiO}_{2}, \mathrm{Al}_{2} \mathrm{O}_{3}$, and $\mathrm{Fe}_{2} \mathrm{O}_{3}$. The sum of $\mathrm{SiO}_{2}$, $242 \mathrm{Al}_{2} \mathrm{O}_{3}$, and $\mathrm{Fe}_{2} \mathrm{O}_{3}$ was $82.9 \%$. LOI and carbon content for CFA were $1.3 \%$ and $2431.1 \%$, respectively. Chemical composition of cement was typical for sulfate 244 resistant cement. Sand was almost pure $\mathrm{SiO}_{2}$.

245 Median particle sizes of cement, FBCFA, M-FBCFA, and CFA were 9.4, 246 15.9, 3.2, and $11.7 \mu \mathrm{m}$, respectively (see Fig. 1). PSD of FBCFA was a little bit 247 narrower compared to cement. Milling of FBCFA clearly decreased the particle size 248 and increased the span of particle size distribution. The PSD of CFA was similar to 249 cement, but it had a higher share of slightly larger particles.

\section{Effect of AEA on fresh state properties of mortars}

251 Flowability of mortars clearly increased with increasing dosage of AEA (Fig. 2).

252 Small air bubbles probably act as "ball bearings" in mortars, which allows particles

253 to bypass each other more easily, leading to decreased viscosity and lower yield

254 stress. It is well known that FBCFA can decrease the flowability of mortar or 255 concrete (Fu et al. 2008; Li et al. 2012; Rissanen et al. 2018; Sata et al. 2007; Sheng 256 et al. 2007). Despite the preliminary trials performed for mortars, flowability of M257 FBCFA was somewhat higher compared to other mixtures. This indicates that SP 258 dosage for M-FBCFA could be even lower than suggested in Table 1, when 
259 targeting similar flowability with other mixtures. This is in line with other studies 260 reporting that milling of FBCFAs can decrease the water requirement of concrete 261 or mortar (Fu et al. 2008; Li et al. 2012; Rissanen et al. 2018). Air entrainment had

262 the lowest impact on flowability of mortars containing FBCFA. Apparently, the 263 irregularly shaped ash particles of FBCFA have an opposite effect on workability.

264 This could be a positive effect in air-entrained concrete as it could stabilize air 265 bubbles and increased viscosity could prevent unwanted loss of entrained air from 266 fresh mortar.

267 Neither un-milled nor milled FBCFA had a significant effect on 268 performance of AEA, unlike CFA, which clearly decreased the effectiveness of 269 AEA (Fig. 3). FBCFA had the same or slightly higher air content compared to the 270 reference (Ref.) when AEA dosage was low. At $0.05 \%$ AEA dosage, Ref. had 271 slightly higher air content than FBCFA or M-FBCFA. When AEA dosage was 272 increased to $0.2 \%$, FBCFA had the highest air content (43\%), while Ref. had 273 slightly lower air content (40\%). Air contents of M-FBCFA were slightly lower 274 than those of Ref. and FBCFA at every AEA dosage. However, the difference 275 compared to Ref. increased as the amount of AEA increased. It is possible that 276 slightly lower viscosity of mortars containing M-FBCFA caused entrained air to 277 escape from fresh mortar. Similarly, high viscosity of mortars containing FBCFA 278 could help to prevent loss of entrained air.

279 Air contents of mortars containing CFA clearly were lower compared to 280 other mortar mixtures. The only exception to this trend was the mortar specimen 281 containing $0.2 \%$ AEA. This specimen had the same air content (40\%) as Ref. It is 282 possible that when AEA dosage is high enough, air content is affected also by the 283 rheology of the mortar, rather than just by AEA concentration. At lower AEA 284 dosages, CFA required approximately two to three times higher AEA dosage to 
285 achieve similar air content as other ashes. CFA probably contains a small amount 286 of unburned carbon, which was enough to absorb a significant amount of AEA. 287 Apparently, the content of unburned carbon is much lower in FBCFA, as low 288 carbon content suggests. Possible variations in the properties, such as accessible 289 surface area and surface chemistry of carbon particles, can also explain why fly 290 ashes had different effects on AEA (Gao et al. 1997; Hachmann et al. 1998; Hill et 291 al. 1997).

292 Air contents of fresh mortars without AEA were 5.6, 6.8, 4.4, and 3.7\% for

293 Ref., FBCFA, M-FBCFA, and CFA, respectively. This result could indicate that

294 FBCFA having highly irregular particle shape could entrap some air in the fresh 295 mixture, while M-FBCFA and CFA had opposite effects. Similar observations were 296 done in the study by Johnson et al. (Johnson et al. 2010) who reported that $20 \%$ 297 cement replacement using conventional coal fly ash slightly reduced the air content 298 of non-air-entrained concrete.

\section{Compressive strength}

300 Air content of fresh mortar correlated well with 28-day compressive strength (Fig. 301 4). Both FBCFA and M-FBCFA had similar compressive strengths compared to 302 Ref. This result suggests that FBCFA and M-FBCFA produced hydration products 303 that had a positive impact on compressive strength. In the case of CFA, pozzolanic 304 reactions were probably slower, which explains why compressive strength of CFA 305 at the age of 28 days was slightly lower.

306 Similarly, compressive strengths measured after F-T experiments correlated 307 well with air content of the fresh mortars (Fig. 5). FBCFA had slightly better 308 compressive strength compared to Ref. at fresh mortar air contents below $20 \%$, 309 which are more relevant for practical use. With higher air contents, however, 310 performance clearly decreased. M-FBCFA had similar compressive strength as Ref. 
311 when air content was low, however, with higher air contents, performance of M-

312 FBCFA seemed to decrease. Compressive strengths of mortars containing CFA

313 were clearly the weakest after the F-T experiment. At $10 \%$ air content, compressive

314 strength was $40 \%$ lower compared to Ref. and even $48 \%$ lower compared to

315 FBCFA. CFA mortar without AEA suffered severe damage during the experiment,

316 and compressive strength could not been determined.

317 It should be noted that all mortars where $0.2 \%$ AEA dosage was used

318 suffered from severe damage during the F-T experiment. For this reason, several

319 compressive strength specimens from these mixes had to be discarded, which

320 naturally decreased the reliability of the data. Fresh mortar air contents exceeding

$32135 \%$ are clearly excessive for practical use. FBCFA mortar containing $0.2 \%$ AEA

322 dosage was destroyed during the F-T experiment, and compressive strength could 323 not been determined.

324 Few studies have reported that milling of coal fly ash from FBC (Li et al.

325 2012; Zhao et al. 2015) and pulverized combustion (Hamzaoui et al. 2016) is

326 beneficial for mechanical properties of mortars when FBCFA is used for partial

327 cement replacement. In this study, such behavior was not observed. The reason for 328 this could be different physical properties of FBCFA originating from biomass 329 combustion as well as different milling parameters. In a study by Zhao et al. (2015), 330 milling increased specific surface area (SSA) from approximately 0.5 to $0.8 \mathrm{~m}^{2} / \mathrm{g}$, 331 and in a study by Hamzaoui et al. (Hamzaoui et al. 2016), from 0.8 to $2 \mathrm{~m}^{2} / \mathrm{g}$.

332 Ohenoja et al. (2016) milled FBCFA from combustion of biomass and peat using 333 pin mill and ball mill. Only pin mill at the highest milling speed was able to increase 334 SSA from 3.1 to $6.7 \mathrm{~m}^{2} / \mathrm{g}$, while ball mill and pin mill at lower speeds had little 335 effect on SSA. Additionally, previous studies (Rissanen et al. 2018) showed that 336 milling of FBCFAs was able to increase SSA only $15 \%$ and $16 \%$. It seems that 
337 milling has very limited effect on SSA of fly ashes, which already have a high

338 surface area. Similarly, some studies reported that milling of fly ash could increase

339 the share of amorphous phases leading to increased reactivity ( $\mathrm{Fu}$ et al. 2008;

340 Hamzaoui et al. 2016; Zhao et al. 2015). On the other hand, Ohenoja et al. (2016)

341 showed that milling did not increase the amount of reactive $\mathrm{CaO}, \mathrm{SiO}_{2}, \mathrm{Al}_{2} \mathrm{O}_{3}$, or

$342 \mathrm{Fe}_{2} \mathrm{O}_{3}$.

\section{Freeze-thaw resistance}

344 The best F-T resistance was achieved with air content of 14\% (see Fig. 6). When

345 air content of fresh mortar was over $30 \%$, F-T resistance decreased rapidly due to

346 weak mechanical properties of mortars. Air entrainment had a positive effect on F-

347 T resistance of mortars with FBCFA, when air content of fresh mortar was around $34812 \%$. In this mixture, compressive strength was even slightly higher after the F-T

349 experiment, compared to specimen, which was not subjected to the experiment.

350 Apparently, AEA dosage provided good protection against F-T cycles. When air

351 content increased, the F-T resistance decreased and the specimen that had an air

352 content of $43 \%$ was destroyed during the experiment. In the relevant air content 353 range (10-20\% for mortars), F-T resistance of M-FBCFA mortars were better or on 354 par with Ref. F-T resistance of all mortars decreased as expected at non-realistically 355 high air contents of $30 \%$ or higher.

356 In the case of CFA, AEA was essential for F-T resistance. Mixture without

357 AEA suffered from severe damage (Fig. 6b), and F-T resistance could not been 358 determined. The reason for this could lie in the combined effect of low strength, 359 high water content, and low air content. Slower reactivity of CFA leads to lower 360 compressive strength compared to other specimens without AEA. Due to slower 361 reactivity, mortars with CFA probably had a higher amount of capillary pores, 362 which contained a higher amount of water, which created higher stress during 
363 freezing. This caused severe damage in this mortar, which had the lowest amount

364 of entrained air. The addition of AEA clearly increased air content and F-T

365 resistance of mortars to similar levels compared to Ref. and other fly ashes. The

366 best result for CFA (97\%) was obtained with AEA dosage of $0.015 \%$, which

367 produced 23\% air content (Fig. 6).

368 AEA also had a positive effect on F-T resistance of the no-ash Ref. F-T

369 resistance of the mixture without AEA was $83 \%$, and the best result (93\%) was

370 obtained when air content of mortar was $18 \%$.

371 Relative dynamic modulus (RDM) as a function of fresh mortar air content

372 (Fig. 7) showed a similar trend with F-T resistance (Fig. 6). FBCFA and M-FBCFA

373 demonstrated the same or better performance than Ref. within the whole data range.

374 RMD clearly decreased in specimens that showed signs of damage during the F-T

375 experiment. However, RDM was clearly a less sensitive measurement of F-T

376 damage compared to compressive strength. In most samples, RDM decreased only

377 slightly from the original $100 \%$, and in some cases, RDM even slightly increased.

378 Even the most deteriorated samples, CFA0 and FBCFA0.2, reached RDM of $72 \%$

379 and $85 \%$, relatively. This could suggest that F-T experiment damages occurred

380 mainly on the surface of the mortars and did not cause internal cracking of the

381 matrix. It is also possible that during the experiment, mortars still absorbed water

382 that could increase the speed of the ultrasonic pulse in the sample.

\section{Conclusions}

384 Milled as well as un-milled wood-peat combustion ashes led to improvement in 385 mortar F-T performance in relevant air contents (10-20\%). This was more evident 386 with the non-milled ash with $10 \%$ air content, which improved F-T performance by $38720 \%$, as measured by UCS after 90 F-T cycles. In addition, the presence of these 
388 ashes did not affect the total amount of entrained air, and therefore did not seem to

389 affect the functioning of AEAs.

390 Ashes from pulverized coal combustion led to decreased F-T performance

391 of the mortars. It increased AEA requirement two to three times, and at $10 \%$ air

392 content, lowered F-T performance by $40 \%$ and led to a fully destroyed sample at $3934 \%$ air content.

\section{Acknowledgements}

395 This work was done under the auspices of the ARCTIC-ecocrete project, which is

396 supported by Interreg Nord EU-program and the Regional Council of Lapland.

397 Jouni Rissanen gratefully acknowledges the financial support from the Fortum

398 Foundation and Tauno Tönning’s Foundation. Mr. Jarno Karvonen and Mr. Jani

399 Österlund are acknowledged for their contributions to the laboratory work.

400 Data Availability Statement

401 All data, models, and code generated or used during the study appear in the 402 submitted article.

403 References

404 “ASTM C138 / C138M-17a, Standard Test Method for Density (Unit Weight), 405 Yield, and Air Content (Gravimetric) of Concrete.” (2017). ASTM $406 \quad$ International.

407 "ASTM C666 / C666M-15, Standard Test Method for Resistance of Concrete to $408 \quad$ Rapid Freezing and Thawing.” (2015). ASTM International.

409 “ASTM C91-05, Standard Specification for Masonry Cement.” (2005). ASTM $410 \quad$ International. 
411 Cyr, M. (2013). "Influence of supplementary cementitious materials (SCMs) on concrete durability.” Eco-Efficient Concrete, 153-197.

413 Dransfield, J. (2003). “Admixtures for concrete, mortar and grout.” Advanced $414 \quad$ Concrete Technology, 3-36.

415 Fu, X., Li, Q., Zhai, J., Sheng, G., and Li, F. (2008). "The physical-chemical characterization of mechanically-treated CFBC fly ash." Cement and Concrete Composites, 30(3), 220-226.

418 Gao, Y.-M., Shim, H.-S., Hurt, R. H., Suuberg, E. M., and Yang, N. Y. C. (1997). "Effects of Carbon on Air Entrainment in Fly Ash Concrete: The Role of Soot and Carbon Black." Energy \& Fuels, 11(2), 457-462.

421 Glinicki, M. A., and Zielinski, M. (2008). "Air void system in concrete containing circulating fluidized bed combustion fly ash." Materials and Structures,

424 Glinicki, M. A., and Zielinski, M. (2009). "Frost salt scaling resistance of concrete containing CFBC fly ash.” Materials and Structures, 42(7), 993-1002.

426 Hachmann, L., Burnett, A., Gao, Y.-M., Robert H., H., and Suuberg, E. M. (1998). "Surfactant adsorptivity of solid products from pulverized-coal combustion

430 Hamzaoui, R., Bouchenafa, O., Guessasma, S., Leklou, N., and Bouaziz, A. (2016). under controlled conditions." Symposium (International) on Combustion, 27(2), 2965-2971.

434 Hewlett, P. (2003). Lea's Chemistry of Cement and Concrete. Elsevier. 
435 Hill, R. L., Sarkar, S. L., Rathbone, R. F., and Hower, J. C. (1997). “An examination of fly ash carbon and its interactions with air entraining agent." Cement and Concrete Research, 27(2), 193-204.

438 Ipatti, A. (1988). "Peat fly ash as a supplementary cementing material in concrete." Nordic concrete research, (7), 152-166.

440 Johnson, A., Catalan, L. J. J., and Kinrade, S. D. (2010). "Characterization and evaluation of fly-ash from co-combustion of lignite and wood pellets for use as cement admixture." Fuel, 89(10), 3042-3050.

443 Józwiak-Niedźwiedzka, D. (2012). "Estimation of Chloride Migration Coefficient in Air-Entrained Concretes Containing Fluidized Bed Combustion Fly Ash / Ocena Współczynnika Migracji Jonów Chlorkowych W Betonach Zawierajacych Popiół Fluidalny.” Archives of Civil Engineering, 58(1), 25-

Kosior-Kazberuk, M. (2013). “Surface Scaling Resistance of Concrete with Fly Ash From Co-Combustion of Coal and Biomass." Procedia Engineering, Modern Building Materials, Structures and Techniques, 57, 605-613.

451 Kosior-Kazberuk, M., and Józwiak-Niedzwiedzka, D. (2010). "Influence of Fly Ash From Co-Combustion of Coal and Biomass on Scaling Resistance of Concrete / Wpływ Popiołu Lotnego Ze Współspalania Wegla I Biomasy Na

456 Li, X., Chen, Q., Huang, K., Ma, B., and Wu, B. (2012). "Cementitious properties and hydration mechanism of circulating fluidized bed combustion (CFBC) desulfurization ashes." Construction and Building Materials, 36, 182-187. 
459 Nagrockienè, D., and Daugèla, A. (2018). "Investigation into the properties of concrete modified with biomass combustion fly ash." Construction and Building Materials, 174, 369-375.

462 Naik, T. R., Kraus, R. N., Yoon-moon Chun, and Botha, F. D. (2005). "CastConcrete Products Made with FBC Ash and Wet-Collected Coal-Ash.”

465 Ohenoja, K., Tanskanen, P., Peltosaari, O., Wigren, V., Österbacka, J., and 466

Rajamma, R., Senff, L., Ribeiro, M. J., Labrincha, J. A., Ball, R. J., Allen, G. C., and Ferreira, V. M. (2015). "Biomass fly ash effect on fresh and hardened state properties of cement based materials." Composites Part B: Engineering, 77, 1-9.

Rissanen, J., Ohenoja, K., Kinnunen, P., and Illikainen, M. (2017). "Partial replacement of portland-composite cement by fluidized bed combustion fly ash.” Journal of Materials in Civil Engineering, 29(8).

Rissanen, J., Ohenoja, K., Kinnunen, P., Romagnoli, M., and Illikainen, M. (2018). "Milling of peat-wood fly ash: Effect on water demand of mortar and rheology of cement paste." Construction and Building Materials, 180, 143- 

1598.

"SFS-EN 1015-3:en. Methods of test for mortar for masonry. Part 3: Determination of consistence of fresh mortar (by flow table)." (1999). Finnish Standards Association.

“SFS-EN 196-1:2016:en. Methods of testing cement. Part 1: Determination of strength.” (2016). Finnish Standards Association.

“SFS-EN 450-1:en. Fly ash for concrete - Part 1: Definition, specifications and conformity criteria.” (2013). Finnish Standards Association.

494 Shearer, C. R., Yeboah, N., Kurtis, K. E., and Burns, S. E. (2010). "Investigation of biomass Co-fired fly ash properties: Characterization and concrete durability performance." 1719-1729.

497 Sheng, G., Zhai, J., Li, Q., and Li, F. (2007). "Utilization of fly ash coming from a CFBC boiler co-firing coal and petroleum coke in Portland cement." Fuel,

500 Wang, S., Llamazos, E., Baxter, L., and Fonseca, F. (2008). "Durability of biomass fly ash concrete: Freezing and thawing and rapid chloride permeability tests." Fuel, 87(3), 359-364.

Wang, Z., and Song, Y. (2016). “Adsorption properties of CFBC ash-cement pastes as compared with PCC fly ash-cement pastes." International Journal of Coal Science \& Technology, 3(1), 62-67.

506 Zhao, J., Wang, D., and Liao, S. (2015). "Effect of mechanical grinding on physical and chemical characteristics of circulating fluidized bed fly ash from coal gangue power plant." Construction and Building Materials, 101, Part 1, 851-860. 